\title{
SARS-CoV-2 Quantitative Real Time PCR and Viral Loads Analysis Among Asymptomatic and Symptomatic Patients: an Observational Study on an Outbreak in Two Nursing Facilities in Campania Region (Southern Italy)
}

\section{Lorena Cardillo}

IZSM: Istituto Zooprofilattico Sperimentale del Mezzogiorno

Claudio de Martinis ( $\nabla$ claudio.demartinis@izsmportici.it)

Istituto Zooprofilattico Sperimentale del Mezzogiorno https://orcid.org/0000-0002-0948-5513

Maurizio Viscardi

IZSM: Istituto Zooprofilattico Sperimentale del Mezzogiorno

Claudia Esposito

IZSM: Istituto Zooprofilattico Sperimentale del Mezzogiorno

\section{Emanuela Sannino}

IZSM: Istituto Zooprofilattico Sperimentale del Mezzogiorno

Gabriella Lucibelli

Istituto Zooprofilattico Sperimentale del Mezzogiorno

Antonio Limone

IZSM: Istituto Zooprofilattico Sperimentale del Mezzogiorno

Roberta Pellicanò

IZSM: Istituto Zooprofilattico Sperimentale del Mezzogiorno

Loredana Baldi

Istituto Zooprofilattico Sperimentale del Mezzogiorno

\section{Giorgio Galiero}

IZSM: Istituto Zooprofilattico Sperimentale del Mezzogiorno

\section{Giovanna Fusco}

IZSM: Istituto Zooprofilattico Sperimentale del Mezzogiorno

\section{Research Article}

Keywords: SARS-CoV-2, COVID-19, viral loads, symptomatic, asymptomatic, age, gender, risk factors

Posted Date: January 7th, 2021 
DOl: https://doi.org/10.21203/rs.3.rs-139370/v1

License: (c) (1) This work is licensed under a Creative Commons Attribution 4.0 International License. Read Full License 


\section{Abstract}

Background: In December 2019 an outbreak of Severe Acute Respiratory Syndrome Coronavirus 2 was first observed in Wuhan, China. The virus has spread rapidly throughout the world creating a pandemic scenario. Several risk factors have been identified, such as age, gender, concomitant diseases as well as viral load. One of the key questions since the beginning of the pandemic, is the role of asymptomatic people in spreading SARS-CoV-2. An observational study in Southern Italy was conducted in order to elucidate the possible role of asymptomatic individuals related to their viral loads in the transmission of the virus within two nursing facilities.

Methods: oro-nasopharyngeal swabs from 179 nursing health care workers and patients were collected. SARS-CoV-2 RT-qPCR was performed and viral loads were calculated by using standard curve. For positive results, a statistical correlation between viral loads, the presence/absence of symptoms, age and gendervariables was investigated.

Results: SARS-CoV-2 was confirmed in the $50.8 \%(n=91)$ of the cases. Median age of positive individuals resulted higher than negative ones. A statistically significant difference $(p<.001)$ was observed for age and gendervariables and over 65 years individuals showed higher susceptibility to SARS-CoV-2 infection than younger ones $(\mathrm{OR}=3.93)$ as well as female $(\mathrm{OR}=2.86)$. Among 91 tested positive, the $70.3 \%$ was symptomatic $(n=64)$ whilst the $29.7 \%$ was asymptomatic $(n=27)$. Median viral loads of asymptomatic individuals were found statistically significant higher than symptomatic ones $(p=.001)$, while no influence was observed in age and gender variables.

Conclusions: A range from $9.2 \%$ to $69 \%$ of confirmed SARS-CoV-2 cases remains asymptomatic, moreover, sporadic transmissions from asymptomatic people are reported, that makes their involvement an important issue to take into account in the spreading control of the virus. An asymptomatic clinical course was observed in the $29.7 \%$ of positive individuals, moreover, median viral loads resulted to be statistically significant when compared to symptomatic ones. Surely, such a relevant frequency should not be ignored in relation to the spread of the disease in an environment which has not only important intrinsic (age, gender, concomitant diseases) but also extrinsic factors such as high population density and close contacts.

\section{Background}

On late December 2019, a novel human Betacoronavirus caused a cluster of severe acute respiratory syndrome (SARS) cases in Wuhan (China). The virus was later named SARS-CoV-2 by the International Committee of Taxonomy [1]. The global spread of the virus has created a pandemic scenario with over 67 million reported cases and 1.5 million deaths worldwide since the start of the pandemic [2]. On January 2020, Italy was detected as the first country where SARS-CoV-2 shifted away from its origins [3], causing 1.7 million cases, with a 48 years median age, and 58.8 thousand deaths [4]. 
The disease clinical course is characterized by several factors, from asymptomatic to mild or severe viral respiratory tract infections, up to systemic inflammation and thrombosis [5]. Several other risk factors have also been identified to affect the disease course, such as gender, concomitant diseases, close contact and age $[5,8]$. Indeed, Centers for Disease Control and Prevention (CDC) has identified 65 years old and older people at a greater risk of hospitalization and death for COVID-19, from 90x higher risk of death for 65-74 years old, up to 630x higher for over 85 years old people [9]. Moreover, Pujadas and colleagues showed that high viral load was correlated to higher mortality rates, suggesting to use quantitative analyses for patient risk-stratification [10], thus, high viral load could act a key role in the severity of COVID-19. These findings were supported by other studies reporting an association between high viral loads and more severe symptoms [6-11, 17]. Otherwise, other studies did not show any statistically significant difference in viral loads between symptomatic and asymptomatic individuals $[10-18,20]$, while Hasanoglu and colleagues showed that higher viral loads were found in asymptomatic patients when compared to symptomatic ones and that, the more the clinical course of the diseases was severe, the lower viral loads were observed, together with a significant negative trend with increasing age [5]. Thus, the clinical relevance of the role of viral loads is still unclear. The aim of this study was to elucidate the dilemma of the viral loads correlation to symptoms, age and gender, for this reason, an observational study was conducted in a SARS-CoV-2 outbreak in two nursing facilities in Campania region, Southern Italy.

\section{Methods}

\section{Subjects and data collection}

An observational study was carried out by the Istituto Zooprofilattico Sperimentale del Mezzogiorno (IZSM) of Portici, Naples (Southern Italy), as part of routine diagnostic activities of COVID-19, aimed to verify the correlation of viral loads to symptoms, age and gender. Combined oro-nasopharyngeal swabs were performed by the Local Health Authorities. Swabs were transferred to the IZSM in Universal Viral Transport Medium (UTM) (Copan, Brescia, Italy), accompanied by an application form that included records, signalling, symptoms and main health state of each tested person.

\section{Nucleic acid extraction and molecular analysis}

Nucleic acid extraction was conducted as follows: in Biosafety Level 3 (BLS-3) laboratories, aliquots of $200 \mu \mathrm{L}$ of UTM were collected from each specimen and submitted to extraction and purification using QIAsymphony DSP Virus/Pathogen Mini Kit (Qiagen, Hilden, Germany) and performed by QIAsymphony automated system (Qiagen) following manufacturer's instructions, eluted in $60 \mu \mathrm{L}$ and stored at $-80^{\circ} \mathrm{C}$ until use.

Notably, SARS-CoV-2 RT-qPCR was performed in BLS-2, using TaqPath COVID-19 CE-IVD RT-PCR Kit (Thermo Fisher Scientific), approved by the World Health Organization (WHO) [21], that simultaneously amplifies 3 viral targets, ORF1ab gene (FAM), N proteine (VIC), S protein (ABY) and MS2 phage (JUN) as internal control. Amplification was carried out in a final volume of $25 \mu \mathrm{L}$ and included $5 \mu \mathrm{L}$ of template, 
TaqPath 1-Step Multiplex Master Mix (4X), probes and specific primer sets for the different SARS-CoV-2 genomic regions. Thermal cycling conditions included an initial Uracil-DNA glycosylase (UNG) incubation step at $25^{\circ} \mathrm{C}$ for 2 minutes, followed by reverse transcription at $53^{\circ} \mathrm{C}$ for $10 \mathrm{~min}$, initial denaturation/enzyme activation at $95^{\circ} \mathrm{C}$ for 2 min, 40 cycles of denaturation at $95^{\circ} \mathrm{C}$ for $3 \mathrm{sec}$ and annealing/extension at $60^{\circ} \mathrm{C}$ for $30 \mathrm{sec}$. The RT-qPCR WAS performed on 7500 Fast Real-Time PCR system (Applied Biosystems, Foster City, USA). Viral loads were calculated by using standard curve, as described elsewhere [10]. To generate the real-time PCR standard curve, appropriate 10-fold serial dilutions of the titrated positive control provided by the RT-PCR Kit were performed in triplicate. A standard curve was obtained by linear regression analysis of the threshold cycle $\left(\mathrm{C}_{t}\right)$ value (y-axis) versus the log of the initial copy number present in each sample dilution (x-axis). PCR efficiency (E) was calculated as $\mathrm{E}=10(1 / \text { slope })^{-1}$.

\section{Statistical analysis}

Univariate models were first used. The variables considered were: results (positive/negative) age $(</>$ 65 years) and gender (male/female). Prevalence was calculated at a 95\% confidence level. A chi-squared test of association was used to obtain the statistical significance level between groups. A correlation within results and age class was performed by using the Kolmogorov-Smirnov normality test in order to assess the statistical distribution of these two variables. Next, the non-parametric Mann Whitney $\mathrm{U}$ test was performed to verify the difference of the median age values in the positive/negative group was statistically significant. For positive results, a correlation between viral loads (copies $/ \mathrm{mL}$ ), the presence/absence of symptoms (symptomatic/asymptomatic), age and gender were investigated. For these variables, Kolmogorov-Smirnov and Mann Whitney $U$ test, were performed, too.

All statistical analyses were performed by using SPSS software, version 24.0 (IBM Corporation). Results were considered statistically significant with a $p$ value $<0.05$.

\section{Results}

On late March 2020, during lockdown, in a nursing facility for elderly people in Naples province and in a rehabilitation facility, located in Benevento province, Campania, region (Southern Italy), suspected onset of COVID-19 symptoms in some patients were reported. A total of 179 combined oro-nasopharyngeal swabs were performed by the Local Health Authorities on patients and health care workers and conducted to the IZSM for diagnostic procedures. SARS-CoV-2 was confirmed in 91 patients (50.8\%). Patient age ranged between 22 and 98 years, with a median of 65 years. They were divided into two categories: "age", under and over 65 years old, that represented the $48 \%(n=86)$ and $52 \%(n=93)$, respectively, and "gender", male and female, $40.8 \%(n=73)$ and $59.2 \%(n=106)$, respectively. Results are reported in Table 1. A statistically significant difference between over and under 65 years old individuals was observed ( $p>$.001) and higher susceptibility to SARS-CoV-2 infection was found for elderly people $(O R=3.93)$. Gender variable showed a statistically significant difference $(p<.001)$ too, and female were found 2.86 folds more susceptible to COVID-19 than male. 
Table 1

Gender and age statistical analysis.

\begin{tabular}{|c|c|c|c|c|c|c|c|c|}
\hline \multirow[t]{2}{*}{ Variable } & \multirow[t]{2}{*}{ Total } & \multicolumn{2}{|c|}{ Positive } & \multirow[t]{2}{*}{$95 \% \mathrm{Cl}$} & \multirow[t]{2}{*}{$x^{2}$} & \multirow[t]{2}{*}{$p$ value } & \multirow[t]{2}{*}{ OR } & \multirow[t]{2}{*}{ OR $95 \% \mathrm{Cl}$} \\
\hline & & $n$ & $\%$ & & & & & \\
\hline Overall & 179 & 91 & 50.8 & $44.04-57.56$ & & & & \\
\hline$>65 y$ & 93 & 62 & 66.6 & $57.02-76.18$ & 19.405 & $<0.001$ & 3.93 & $2.11-7.31$ \\
\hline$<65 y$ & 86 & 29 & 36.7 & $26.52-46.88$ & & & & \\
\hline Female & 106 & 65 & 61.3 & $52.03-70.57$ & 11.43 & $<0.001$ & 2.86 & $1.54-5.31$ \\
\hline Male & 73 & 26 & 35.6 & $24.62-46.58$ & & & & \\
\hline
\end{tabular}

Data analyses concerning age, showed that average and median age of tested negative patients (57 years) were lower than positive ones (75 years) (Table 2). Kolmogorov-Smirnov normality test was performed and it demonstrated that age variables were not normally distributed $(p=.001)$, next, Mann Whitney $\mathrm{U}$ test verified that the difference between median values of age registered both in positive and negative groups was statistically significant $(p=.001)$.

Table 2

Average and median age evaluation of negative and positive individuals.

\begin{tabular}{|c|c|c|c|c|c|c|}
\hline & \multicolumn{6}{|l|}{ AGE } \\
\hline & Average & Median & Min & Max & SD & $95 \% \mathrm{Cl}$ average age \\
\hline Negative & 59 & 57 & 22 & 98 & 20 & $55-64$ \\
\hline Positive & 70 & 75 & 24 & 96 & 18 & $66-74$ \\
\hline
\end{tabular}

The presence/absence of symptoms was evaluated for positive tested. Among 91 individuals, the $70.3 \%$ was symptomatic $(n=64)$ whilst the $29.7 \%$ was asymptomatic $(n=27)$. Viral loads of the samples were analyzed. Results are reported in Table 3. Viral loads on tested positive individuals ranged from 699 to $4.71 \times 10^{8}$ copies per $\mathrm{mL}$, with a median of $1.46 \times 10^{5}$. Asymptomatic group showed higher median viral load values $\left(1.14 \times 10^{7}\right)$ than symptomatic one $\left(3.39 \times 10^{4}\right)$. Kolmogorov-Smirnov test showed that the viral load variable was not normally distributed $(p=.001)$ followed by the non-parametric Mann Whitney $U$ test performed on median viral load values and a statistically significant difference was found ( $p$ $=.001)$. On the other hand, viral load was not influenced by age and gender variables. 
Table 3

Evaluation of viral loads of tested positive individuals.

\section{Viral loads (copies/mL)}

\begin{tabular}{|c|c|c|c|c|c|c|}
\hline Variable & Average & $95 \% \mathrm{Cl}$ & Median & Min & Max & SD \\
\hline Overall & $\begin{array}{l}2,52 \mathrm{E}+ \\
07\end{array}$ & $\begin{array}{l}1.05 E+07-3.99 E+ \\
07\end{array}$ & $\begin{array}{l}1,46 \mathrm{E}+ \\
05\end{array}$ & $\begin{array}{l}6,99 \mathrm{E}+ \\
02\end{array}$ & $\begin{array}{l}4,71 E+ \\
08\end{array}$ & $\begin{array}{l}7,01 \mathrm{E}+ \\
07\end{array}$ \\
\hline Asymptomatic & $\begin{array}{l}3,99 \mathrm{E}+ \\
07\end{array}$ & $\begin{array}{l}1,20 \mathrm{E}+07-6,77 \mathrm{E}+ \\
07\end{array}$ & $\begin{array}{l}1,14 \mathrm{E}+ \\
07\end{array}$ & $\begin{array}{l}1,30 \mathrm{E}+ \\
04\end{array}$ & $\begin{array}{l}2,67 \mathrm{E}+ \\
08\end{array}$ & $\begin{array}{l}7,03 E+ \\
07\end{array}$ \\
\hline Symptomatic & $\begin{array}{l}1,90 \mathrm{E}+ \\
07\end{array}$ & $\begin{array}{l}1,47 E+06-3,65 E+ \\
07\end{array}$ & $\begin{array}{l}3,39 E+ \\
04\end{array}$ & $\begin{array}{l}6,99 \mathrm{E}+ \\
02\end{array}$ & $\begin{array}{l}4,71 E+ \\
08\end{array}$ & $\begin{array}{l}7,02 \mathrm{E}+ \\
07\end{array}$ \\
\hline$>65 y$ & $\begin{array}{l}3,09 \mathrm{E}+ \\
07\end{array}$ & $\begin{array}{l}1.05 E+07-5.13 E+ \\
07\end{array}$ & $\begin{array}{l}1,53 \mathrm{E}+ \\
05\end{array}$ & $\begin{array}{l}7,17 \mathrm{E}+ \\
02\end{array}$ & $\begin{array}{l}4,71 \mathrm{E}+ \\
08\end{array}$ & $\begin{array}{l}8,02 \mathrm{E}+ \\
07\end{array}$ \\
\hline$<65 y$ & $\begin{array}{l}1,85 \mathrm{E}+ \\
07\end{array}$ & $\begin{array}{l}4.32 E+05-3.66 E+ \\
07\end{array}$ & $\begin{array}{l}1,38 \mathrm{E}+ \\
05\end{array}$ & $\begin{array}{l}6,99 \mathrm{E}+ \\
02\end{array}$ & $\begin{array}{l}1,91 \mathrm{E}+ \\
08\end{array}$ & $\begin{array}{l}4,75 \mathrm{E}+ \\
07\end{array}$ \\
\hline Female & $\begin{array}{l}2,34 \mathrm{E}+ \\
07\end{array}$ & $\begin{array}{l}5.66 \mathrm{E}+06-4.11 \mathrm{E}+ \\
07\end{array}$ & $\begin{array}{l}6,17 \mathrm{E}+ \\
04\end{array}$ & $\begin{array}{l}6,99 \mathrm{E}+ \\
02\end{array}$ & $\begin{array}{l}4,71 E+ \\
08\end{array}$ & $\begin{array}{l}7,16 \mathrm{E}+ \\
07\end{array}$ \\
\hline Male & $\begin{array}{l}2,96 \mathrm{E}+ \\
07\end{array}$ & $\begin{array}{l}2.94 \mathrm{E}+06-4.63 \mathrm{E}+ \\
07\end{array}$ & $\begin{array}{l}4,44 \mathrm{E}+ \\
05\end{array}$ & $\begin{array}{l}1,34 \mathrm{E}+ \\
03\end{array}$ & $\begin{array}{l}2,46 \mathrm{E}+ \\
08\end{array}$ & $\begin{array}{l}6,60 \mathrm{E}+ \\
07\end{array}$ \\
\hline
\end{tabular}

\section{Discussion}

The different role of asymptomatic and symptomatic individuals in the spread of SARS-CoV-2 infection is reported in several papers but how they could spread the disease has not been definitively clarified [22]. A range from $9.2-69 \%$ of confirmed SARS-CoV-2 cases is reported to remain asymptomatic [10-19-23], moreover, sporadic transmissions from asymptomatic people are described [10-24- 25], that makes their involvement an important issue to take into account in the spreading control of the virus. Some surveys have hypothesized the rule of super spreaders during infection outbreaks. Kumar and colleagues identified clinical and social characteristics of these super spreaders, such as heavy dose of infection and more viral shedding and may have more severe cough, thereby they are more likely able to spread the infection; social habits, which increases the possibility of transmission, are individuated in travelling to many places, public gathering, working in crowded places or in confined spaces and hospital staff is included in the list of possible super spreader [26], indeed, health care institutes have been identified as the fourth most considerable causes of disease spreading [27] thus it should also be supposed that high density settings are at viral circulation high risk. Other risk factors, such as age, gender, concomitant diseases and viral load, are frequently discussed. In fact, elderly people are supposed to be particularly susceptible to the infection, especially in age class over 65 years [9-18-27]. The role of asymptomatic as a possible super spreader is unclear, in fact some authors has described various scenarios in which the viral load is higher in symptomatic elderly people $[6-11-13,17-27]$ instead of other cases where 
these findings were observed in asymptomatic ones [5], that finds accordance with Ra et al. which found that asymptomatic individuals showed persistent positive upper respiratory traits [19].

In this work we will try to elucidate the spread of infection in two nursing facilities during the Italian lockdown first part occurred in late March 2020. We could suppose that the virus, after the infection establishment inside these facilities, circulated among health care workers and patients and caused a high infection rate $(50.8 \%)$. It is notable that, because of the lockdown, all the people involved were necessary not able to move along and the use of Personal Protective Equipment (PPE) was mandatory.

Notably, observing the overall data, negative group showed mean and median age values lower than the positive group and after verification, age and gender variables influenced the statistical analyses. Elderly and female groups are confirmed to have higher frequencies of SARS-CoV- 2 infection, thus age and gender could be considered important risk factors, as already described by other authors [5-18-27]. A non-negligible percentage of positive individuals (29.7\%) showed an asymptomatic clinical course, moreover, median viral loads resulted to be statistically significant when compared to symptomatic ones, corroborating other authors' findings [5]. These observations could suggest their possible role in viral circulation inside the nurseries. Surely, such a relevant frequency should not be ignored, mostly in relation to the spread of the disease, especially in an environment, which certainly has not only important intrinsic (age, gender, concomitant diseases) but also extrinsic factors such as high population density and close contacts.

It is strongly controversial the asymptomatic stage evolving in symptomatic, as well as the viral loads in both classes. A distinction between asymptomatic and pre-symptomatic stages can currently only be made retrospectively, after the occurrence or non-occurrence of clinical symptoms [28]. Diagnostic tools cannot distinguish between the two infection stages, as, asymptomatic individuals can show radiographic evidences [29].

\section{Conclusions}

During the first phase of the Italian pandemic caused by SARS-CoV-2 (March-May 2020), on WHO recommendation, oro-pharyngeal swabs were performed only in symptomatic subjects with severe acute respiratory syndrome or in paucisymptomatic patients with epidemiological correlations to other infected. To date, Italian surveillance continues to be somehow on a voluntary basis, but due to the results of many international papers, the role of asymptomatics can be no longer ignored. It is therefore necessary to extend epidemiological surveillance to wider cohorts. Certainly, nursing homes and hospitals are of primary importance as well as schools, gyms, and all places where necessary gatherings occur. Tracking, detection and timing of asymptomatic case could reduce the cumulative number of disease cases. Public health measures should be improved to address this challenge.

\section{Abbreviations}


SARS-CoV-2: Severe Acute Respiratory Syndrome- Coronavirus-2.

COVID-19: Coronavirus disease 19

WHO: World Health Organization

CDC: Center of Disease Control and Prevention

IZSM: Istituto Zooprofilattico Sperimentale del Mezzogiorno

RT-qPCR: Reverse transcriptase quantitative polymerase reaction

BLS: Biosafety Level

UTM: Universal Viral Transport Medium

UNG: Uracil-DNA glycosylase

PPE: Personal Protective Equipment

OR: Odds ratio

Cl: Confidence Intervals

SD: Standard Deviation

\section{Declarations}

\section{Ethics approval and consent to participate}

No study participants were involved in the preparation of this article, that was conducted during routine analysis. Moreover, the Istituto Zooprofilattico Sperimentale del Mezzogiorno (IZSM) was designated by the National Ministry of Health as official laboratory for the diagnosis of SARS-CoV-2, thus, for national regulation and internal policy, ethic approval was deemed unnecessary. IZSM is part of Italian IZS labs network and provide support to Public Health services to meet the extraordinary surge in demand for diagnostic testing of human samples for SARS-CoV-2 by making available appropriately equipped and competent veterinary laboratories in accordance to the guideline (Veterinary Laboratory Support to the Public Health Response for COVID-19) described by the World Organization for Animal Health (OIE).

https://www.oie.int/fileadmin/Home/eng/Our_scientific_expertise/docs/pdf/COV19/A_Guidance_for_animal_health_laboratories_1April2020.pdf

\section{Consent for publication}

Not applicable 
Availability of data and materials

The dataset supporting the conclusions of this article is included within the article.

\section{Competing interests}

The authors declare they have no competing interests that could have influenced the work.

\section{Funding}

This research did not receive any specific grant for funding agencies in the public, commercial, or not-forprofit sectors.

\section{Authors' contributions}

All the authors equally contributed to the study. LC, CDM and LB drafted the manuscript; GF, GG and AL conceded and revised the study; MV, GL, CE and ES conducted the virological exams, RP conducted the statistical analysis.

\section{Acknowledgements}

The authors would like to thank Dr. Alessio Sepe for the cooperation.

\section{References}

1. Yuen KS, Ye ZW, Fung SY, et al. SARS-CoV-2 and COVID-19: The most important research questions. Cell Biosci. 2020;10:40. doi:10.1186/s13578-020-00404-4.

2. WHO Coronavirus Diseases COVID-19 Dashboard. https://covid19.who.int/ . Accessed 9 December 2020.

3. Giovanetti M, Angeletti S, Benvenuto D, Ciccozzi M. A doubt of multiple introduction of SARS-CoV-2 in Italy: A preliminary overview. J Med Virol. 2020;92(9):1634-1636. doi:10.1002/jmv.25773.

4. IstitutoSuperiore di Sanità (ISS). COVID-19 integrated surveillance data in Italy. https://www.epicentro.iss.it/coronavirus/sars-cov-2-dashboard. Accessed 9 December 2020.

5. Hasanoglu I, Korukluoglu G, Asilturk D, et al. Higher viral loads in asymptomatic COVID-19 patients might be the invisible part of the iceberg [published online ahead of print, 2020 Nov 24]. Infection. 2020;1-10. doi:10.1007/s15010-020-01548-8.

6. Zheng S, Fan J, Yu F, et al. Viral load dynamics and disease severity in patients infected with SARSCoV-2 in Zhejiang province, China, January-March 2020: retrospective cohort study. BMJ. 2020;369:m1443. doi:10.1136/bmj.m1443.

7. Jing QL, Liu MJ, Zhang ZB, et al. Household secondary attack rate of COVID-19 and associated determinants in Guangzhou, China: a retrospective cohort study. Lancet Infect Dis. 2020;20(10):11411150. doi:10.1016/S1473-3099(20)30471-0. 
8. Wilkinson $\mathrm{K}$, Chen $\mathrm{X}$, Shaw S. Secondary attack rate of COVID-19 in household contacts in the Winnipeg Health Region, Canada [published online ahead of print, 2020 Nov 17]. Can J Public Health. 2020;1-5. doi:10.17269/s41997-020-00451-x.

9. Centers for Disease Control and Prevention (CDC). COVID-19 (Coronavirus disease). People at increased risk. https://www.cdc.gov/coronavirus/2019-ncov/need-extra-precautions/olderadults.html\#anchor_1606159374271. Accessed 16 December 2020.

10. Pujadas E, Chaudhry F, McBride R, et al. SARS-CoV-2 viral load predicts COVID-19 mortality. Lancet Respir Med. 2020;8(9):e70. doi:10.1016/S2213-2600(20)30354-4.

11. Lescure FX, Bouadma L, Nguyen D, et al. Clinical and virological data of the first cases of COVID-19 in Europe: a case series [published correction appears in Lancet Infect Dis. 2020 May 19;:] [published correction appears in Lancet Infect Dis. 2020 Jun;20(6):e116]. Lancet Infect Dis. 2020;20(6):697-706. doi:10.1016/S1473-3099(20)30200-0.

12. Liu Y, Yan LM, Wan L, et al. Viral dynamics in mild and severe cases of COVID-19. Lancet Infect Dis. 2020;20(6):656-657. doi:10.1016/S1473-3099(20)30232-2.

13. Pan Y, Zhang D, Yang P, Poon LLM, Wang Q. Viral load of SARS-CoV-2 in clinical samples. Lancet Infect Dis. 2020;20(4):411-412. doi:10.1016/S1473-3099(20)30113-4.

14. Shi F, Wu T, Zhu X, et al. Association of viral load with serum biomakers among COVID-19 cases. Virology. 2020;546:122-126. doi:10.1016/j.virol.2020.04.011.

15. To KK, Tsang OT, Leung WS, et al. Temporal profiles of viral load in posterior oropharyngeal saliva samples and serum antibody responses during infection by SARS-CoV-2: an observational cohort study. Lancet Infect Dis. 2020;20(5):565-574. doi:10.1016/S1473-3099(20)30196-1.

16. Yu F, Yan L, Wang N, et al. Quantitative Detection and Viral Load Analysis of SARS-CoV-2 in Infected Patients. Clin Infect Dis. 2020;71(15):793-798. doi:10.1093/cid/ciaa345.

17. Yu X, Sun S, Shi Y, Wang H, Zhao R, Sheng J. SARS-CoV-2 viral load in sputum correlates with risk of COVID-19 progression. Crit Care. 2020;24(1):170. doi:10.1186/s13054-020-02893-8.

18. Lavezzo E, Franchin E, Ciavarella C, et al. Suppression of a SARS-CoV-2 outbreak in the Italian municipality of Vo'. Nature. 2020;584(7821):425-429. doi:10.1038/s41586-020-2488-1.

19. Ra SH, Lim JS, Kim GU, Kim MJ, Jung J, Kim SH. Upper respiratory viral load in asymptomatic individuals and mildly symptomatic patients with SARS-CoV-2 infection [published online ahead of print, 2020 Sep 22]. Thorax. 2020;thoraxjnl-2020-215042. doi:10.1136/thoraxjnl-2020-215042.

20. Lee S, Kim T, Lee E, et al. Clinical Course and Molecular Viral Shedding Among Asymptomatic and Symptomatic Patients With SARS-CoV-2 Infection in a Community Treatment Center in the Republic of Korea [published online ahead of print, 2020 Aug 6]. JAMA Intern Med. 2020;180(11):1-6. doi:10.1001/jamainternmed.2020.3862.

21. WHO, Detecting SARS-CoV-2.

https://www.who.int/diagnostics_laboratory/200922_eul_sars_cov2_product_list.pdf?ua=1. Accessed 15 December 2020. 
22. Oran DP, Topol, EJ. Prevalence of Asymptomatic SARS-CoV-2 Infection : A Narrative Review.Annals of internal medicine, 2020:173(5), 362-367. https://doi.org/10.7326/M20-3012.

23. Kronbichler A, Kresse D, Yoon S, Lee KH, Effenberger M, Shin Jl. Asymptomatic patients as a source of COVID-19 infections: A systematic review and meta-analysis. Int J Infect Dis. 2020;98:180-186. doi:10.1016/j.ijid.2020.06.052.

24. Bai Y, Yao L, Wei T, et al. Presumed Asymptomatic Carrier Transmission of COVID-19. JAMA. 2020;323(14):1406-1407. doi:10.1001/jama.2020.2565.

25. Hoehl S, Rabenau H, Berger A, et al. Evidence of SARS-CoV-2 Infection in Returning Travelers from Wuhan, China. N Engl J Med. 2020;382(13):1278-1280. doi:10.1056/NEJMc2001899.

26. Kumar S, Jha S, Rai SK. Significance of super spreader events in COVID-19. Indian J Public Health. 2020;64(Supplement):S139-S141. doi:10.4103/ijph.IJPH_495_20.

27. Liu T, Liang W, Zhong H, et al. Risk factors associated with COVID-19 infection: a retrospective cohort study based on contacts tracing. Emerg Microbes Infect. 2020;9(1):1546-1553. doi:10.1080/22221751.2020.1787799.

28. Ooi EE, Low JG. Asymptomatic SARS-CoV-2 infection.Lancet Infect Dis. 2020;20(9):996-998. doi:10.1016/S1473-3099(20)30460-6.

29. Long QX, Tang XJ, Shi QL, et al. Clinical and immunological assessment of asymptomatic SARSCoV-2 infections. Nat Med. 2020;26(8):1200-1204. doi:10.1038/s41591-020-0965-6. 